\title{
APPLICATION OF AERIAL PHOTOGRAPHY TO LOGGING OPERATIONS
}

\author{
By D. W. Hudson \\ Department of Lands and Forests, Nova Scotia.
}

\section{GENERAL}

$\mathrm{O}$

NE of the primary uses of aerial photography as applied to forestry has been for timber cruising and forest inventory purposes. This has been the chief reason why a large percentage of the timber limits have been photographed, because the desired information can be gathered quickly and cheaply. However, it was soon discovered by operating companies that the photographs also contained a wealth of information which was of value when applied to logging operations. In fact, this was far in excess of their value for forest inventories. If the photographs have been obtained for cruising purposes, this additional logging data is available with. out any additional cost to the operator as the cost of the photographs is absorbed by the cruise.

Motor roads, hauling roads, dams, camps, stream improvements and other permanent improvements in connection with logging operations can be laid out with the aid of aerial photographs so as to render the greatest value in logging the limits as a whole rather than only a small restricted portion, which is often the case at present. Such improvement work can often be conducted at a greatly reduced cost because much of the preliminary work is done in the office by using aerial photographs under the stereoscope.

With the stereoscope, it is sometimes possible to locate a route to transport wood from one watershed to another, with a resultant large saving in transportation costs.

The application of aerial photographs to logging operations have proved to be of benefit: (1) to the operator; (2) in the preparation of operating plans, (3) motor, portage- and haulingroad location; (4) cut location; and (5) location of dams, camps, and stream improvements. These benefits are discussed separately.

\section{BENEFIT TO THE OPERATOR}

One of the chief advantages of aerial photography is that it brings the forest to the operator's office. If he wants any specific information, all he has to do is refer to the pictures. As these depict what is actually on the ground, if correctly interpreted, they give him the most reliable information possible. He cannot be misled by false reports and has every confidence in letting his logging contracts. 
With the photographs, the operator has a "bird's-eye" view of the whole operation and is able to plan this to the best advantage. He is not limited to the small area actually seen when walking over the ground. With the stereoscope, he is able to see the country in relief and appreciate more fully the logging problems. Thus, he is better able to set a fair price, when giving the contracts for operating.

Also, he can study his operations in the office so that when he does make an inspection trip, he knows exactly what to look for. This will save him considerable time which can be devoted to other duties.

The operator can discuss the work more intelligently with his walking boss and foremen as, by using the pictures, they can show him exactly the problems they are up against and how they plan to solve them. This applies particularly to stream improvements, road location, etc.

The operator has a more accurate map of the district than he would ordinarily have if photographs were not used in its compilation.

\section{The Preparation of Operating Maps}

Operating maps are those which are designed specially to cover the log. ging operation in a certain area, usually a single drainage or operating unit. This is usually the area which can be cut from one camp and the practice has been to compile the map for that individual area.

These maps contain all the available data on the area and, consequently, they are much more detailed than the ordinary cruise maps. They are prepared for the use of the operator, walking boss, cut inspector, and camp foreman or contractor.

Due to the amount of information which must be shown on these plans, they are usually compiled at a scale of ten chains to an inch. This scale is double that of the ordinary cruise maps. As they are used as the basis for compiling the operating plans, it is first necessary to enlarge, from these cruise maps, the area covered by the operating unit to the desired scale by means of the pantograph.

The photographs of the area in question are then placed under the stereoscope and the forest types are studied. These types can usually be further divided to give more detail as to the quality and quantity of, the wood. Good cutting chances are separated from poor cutting chances in the same forest type. These types are usually sub-divided into three main classes:

(1) Good -15 cords and up per acre.

(2) Medium-6 to 15 cords per acre.

(3) Poor -up to 6 cords per acre.

All small areas of cut and blow which were too small to show on the ordinary cruise map are outlined and typed on the operating plan.

Due to the relief which can be seen under the stereoscope, the direction and degree of slope can readily be determined. The direction of the slope is marked on the photographs by arrows made with a green pencil. Five general classes are used to indicate the degree of slope. These are: 


\section{FORESTRY CHRONICLE}
(1) flat
-(F) $0 \%$
(2) gentle $-(\mathrm{G}) \quad 0 \quad-10 \%$
(3) medium -(M) $10-40 \%$
(4) steep -(S) $40 \quad-80 \%$
(5) precipitous-(P) $80-100 \%$

These slopes are marked on the direction arrow. This information is then transferred to the enlarged plan.

In addition, all heights of land can be marked on the photos when they are viewed stereoscopically. This includes major, intermediate and all minor heights, even those between runs. A blue pencil is used to denote the height of land. Prominent hilltops are marked by a circle. Low spots in the height of land are marked by heavy arrows, one on each side of the height. These low spots are very important as it is sometimes possible to bring wood from one watershed to another through them. This can be seen by studying the photographs when the operations are being planned. In an operation which comes to mind, one low spot could be seen and it was thought that the wood could be hauled to the next watershed with little difficulty. There were sixteen million feet of lumber on this compartment. This wood was expensive to drive by natural outlet. By utilizing the low spot, it could be landed on a lake which practically eliminated a long, costly drive. In order to do this, the wood had only to be hauled a few miles further. The low spot was examined on the ground and it was found that there was only one adverse grade of three percent for three chains. Thus it was possible to haul the wood over the height of land. When logging started in that compartment, plans were made to haul the wood by that route. This resulted in a large saving to the operator. Without the photographs there is a possibility that this low spot might have been discovered later on as the operation progressed, but it is doubtful that the wood would have been hauled through it. Thus, in this single case, the photographs proved of inestimable value to the logging operation and saved the operator many times the cost of having this limit photographed.

While the heights of land are being located on the photographs, the heads of small brooks, all runs and depressions, should be shown. These are of considerable importance as they indicate the location of the main and branch hauling roads. These can be located on the maps. From the maps, the bearings and distances can be computed and the roads located by a compass and pace survey. If this is done, then the roads can be placed in their logical locations at the proper economic intervals. The cutting of hauling roads is an expensive proposition and, if too many roads are cut, this adds a considerable expense to the cost of the operation.

All cruise lines together with tie points are shown on the operating map. These are quite important, particularly the tie points, as they are of assistance in correlating points on the ground with those of the photograph and map. The volume of timber is shown in cords per acre for each plot on the cruise line. In addition, the area, stand per acre and total volume is shown 
for each type on the map. Thus, the operator can see at a glance just how much wood there is in each type. Any other information, such as conditions of ground, etc., is also added to the map.

A set of photographs is provided for each camp. These cover the area which is to be cut from that camp. They are put together to form a rough mosaic map and are usually mounted under glass on the desk in the camp office. Thus, they give the contractor a picture of the country in which he is cutting and are supplementary to the map. They are also available for the cut inspector when he requires them for mapping the cut-over areas.

In some operations, the whole job has been laid out in the office with the aid of the photographs, stereoscope and Zeiss plotting stereometer. By use of this latter instrument, together with the stereoscope, a form map showing the contours of the ground is first compiled. Hauling roads are then located on the photographs. These are located as to slope and also so that they would be in the best position to give the greatest coverage of the country to be cut over. They are located approximately ten chains apart. Landings are also located. This information is then transferred to the map. Bearings and distances are compiled for the roads. These main hauling roads are then located on the ground by means of a pocket compass and pace survey and their locations are spotted. In one particular job, the roads were roughly made with a bulldozer as the wood was to be hauled in long lengths by means of a tractor and sulky to the landings where it was cut into four foot wood. All roads were found to be satisfactory and no roads were built unnecessarily. Thus, as it was planned properly, the operation was an economical one.

\section{ROAD LOCATION}

The location of the roads, particularly summer truck roads for portaging supplies, is very important in the planning of an operation and this should be very carefully done. If a road is poorly located, it adds materially to the cost of portaging supplies and equipment. Thus, in locating a road, all information possible should be made available to the person locating the road.

Aerial photographs have proved very beneficial for road location. In fact, it is another of the important uses to which they can be put. They are considered so essential by some companies that they will have an area photographed specially for this purpose before they will locate a road if it is to be used for any length of time.

The chief advantage of the photographs is that, under the stereoscope, they show the ground in relief. Thus, the steep hills and other topographic features can be seen. It is also possible to indicate ground conditions by the nature of the forest, i.e., cedar swamps, etc. On this account the most suitable routes can be chosen simply by examining the photographs. This work can be done in the office, preliminary to locating the road on the ground:

Not only can this work be planned in the office but the person in charge of the location knows that the road is placed in the best possible location. 
Also, only predetermined rcutes are examined on the ground and the crew is not travelling blindly over the country locating the road by trial and error. This results in considerable saving in time, money and labor. The writer was able to locate ten miles of road on the ground in very difficult country and stake it out in a week with the aid of the photographs. If they had not been available, this work would have taken at least a month and it is just questionable if the best route could have been located even in that time.

\section{Procedure}

1. The first step is to decide upon the points of origin and termination of the road. These are located on a map and a straight line is drawn between these points. This is the shortest distance for the road and it should be located as closely as possible to that line.

2. The photographs covering the area are then placed on a table and made into a rough mosaic. The points of origin and termination are then located on the pictures. These are joined by a line which serves as a guide for the road location on the photographs.

3. The photographs are studied under the stereoscope. The road is then located as closely to the guide line as possible. This, of course, depends on the hills and soft places which are encountered along this route. Grades of over fifteen percent should be avoided as should all soft places if they are of any length. It has been found that the best location for a road is on either the hill top or side hill as the drainage is usually better in these places. If it can be placed on a side hill, only one ditch has to be made.

If necessary, several locations, or parts of locations, could be plotted. These should be marked on the photographs with different colored pencils so that they can be distinguished from each other. Thus, if one route does not prove feasible, an alternate one can be investigated.

4. The magnetic meridian is then marked on the photographs. The various locations are drawn in as straight tangents and their intersections or stations marked by letters. The bearings and distances of these tangents are then computed. These are marked on the back of the photographs so that they will always be available for use in the field. It is much better if these stations can be located at or near some prominent point on the photograph, which can be easily identified, as these act as checks for the road location on the ground, because it is essential to have the photographic and ground locations agree as closely as possible. Sometimes if there is a slight divergence between these locations, it will make a big difference in the percentage of grade in the road. This completes the preliminary work in the office.

5. The next step is to investigate the various routes on the ground. This preliminary investigation should be made in the winter as the leaves are off the hardwoods at that time of the year and the investigator can see farther in the woods. Also travelling is usually better then. This preliminary survey is usually made with a pocket compass, and the distance is paced. In case some difficulty is encountered, a pocket stereoscope is taken along so that the photographs can be studied if so desired. The route is 
lightly spotted so that it can be picked up when the final survey is made. A hand level is used to determine the percent of the grades on the hills to ensure that these do not exceed that decided upon as the limiting grade. From. this survey, the best location for the final survey is decided upon.

If it is necessary to locate a road on a very steep side hill, the following procedure was found to work very satisfactorily. The maximum grade for the hill is first decided. Usually this should not be more than 15 per cent. The rodman will then go up the hill about a chain ahead of the instrument man who is using an Abney Hand Level to determine the grade. The instrument man sets the level at the desired percent. He then sights on the rodman. This man moves either up or down the hill, as the case may be, until he is in the proper position to give the required grade. The axemen will then cut out a line to the rodman. The instrument man will then move up to the position held by the rodman and the above procedure is repeated. This is carried on until the road is located over the steep part of the hill.

On the final location, the bearings are run off with a staff compass and the distance between stations are chained. The line should be well cut out and pickets established at not more than one chain intervals. These indicate the center line of the road and act as a guide to the road construction crew. The degree of slope is taken every two chains so that a profile of the road location may be plotted if required.

When this survey has been completed, the forest engineer should go back over the location and examine it very thoroughly to make sure that it is in the most suitable location. It has been found that considerable improvement can sometimes be made if the centre line of the road can be changed a few feet to one side or the other in some locations. This slight change may effect appreciable savings in the cost of construction of the road.

It has been the experience of the writer that the person locating the road should spend as much time as possible with the construction crew. Soft spots and springs, whose presence is not suspected when the road is located, become evident when the road is bulldozed. These may sometimes be avoided by making minor changes which may result in considerable saving in the cost of construction.

Curves are also run in after the final location has been made. These can usually be placed by eye. The required degree of curve depends upon the sharpness of the angle between the tangents. The procedure usually followed by the writer is to set a point four or five chains on each side of the turning point. This indicates the start and end of the curve. One man follows the original survey so that the person setting the pickets in the curve will have an idea how far away he is from. it. The pickets for the curve are lined up by eye with each other and the distance from the original line. Diagrams of tangent offsets for different degrees of curves are sometimes of benefit. The offset distances are measured with a tape. With a little practice very accurate work in locating the curves can be done by this method. 
A curve should be kept as gradual and as long as possible on account of the speed with which the traffic travels on the road.

Care should be taken with regards to soft places in a road. Quite often it is much better to build a "mat of brush" and fill in soft places than to construct a road around it. This, of course, depends on the length of soft spot, material available and the length of road required to avoid it.

In locating the road, it is of paramount importance to keep it as straight as possible, particularly on the hills. If there is a curve on the hill, it is much harder to haul up than if the grade were steeper but the road straight. Also a road may be built to be used for a long period and there may be considerable improvement in automotive equipment in that time. Consequently, a road with a low grade which is constructed by sacrificing straight. ness may be poorly located a few years hence.

\section{Cut LOCATION}

The photographs are also used for mapping cut over areas. The cut inspector carries them in the field and the cuts are located on the pictures in. stead of the maps. With the photographs, the inspector has a better picture of the ground on which the cutting has taken place. Consequently, he is in a better position for mapping these areas. Ties can be more easily located.

The magnetic meridian is marked on the photographs to aid the inspector in plotting cruise lines through the cut. A few of these lines are necessary to measure the residual stand.

Some companies map the cut-over areas by having them photographed every year. In this way, the areas are mapped more accurately than by ground methods. In some instances, the difference amounted to as much as ten per cent between aerial and ground methods. Any patches of wood which have been cut show up very plainly on the pictures.

As these photographed areas were only small, large scale pictures were taken. The area which is photographed included that in which it is planned to carry on the next season's operation. Consequently, they have the most up-to-date information in detail on this as well as having the cuts mapped. They have found this to be most satisfactory and well worth the cost.

\section{Dams, Camps and Stream Improvements}

Dam Sites can be located by studying the photographs under the stereoscope. The whole length of the brook can be seen in detail. Any falls or other features such as steep, narrow banks with flats behind them show clearly on the pictures. Thus, the best locations for a dam site are evident as it is soon seen where the features necessary for this type of stream improvement are located. Consequently, only these locations are examined on the ground. This saves considerable time and expense in the location of these sites.

Camp Sites are located similarly to dam sites. It is frst decided where the camp is to be approximately located. Then the photographs are studied. and the most suitable site in the vicinity is chosen. Sometimes a change is 
made on account of some feature which can be seen in the picture, such as a low spot in the height of land, whereby additional wood could be cut from the camp if the location was changed slightly.

Stream Improvements are also evident from the photographs. This consists chiefly of places where a stream can be straightened to eliminate a crooked portion of the river, such as an ox-bow or a place where it is necessary to build cribworks. The necessity of these improvements can be explained more easily to the management if they are shown a picture of conditions as they exist on the ground and the benefit to be derived from that improvement.

Thus, it is very evident, from the above, that the photographs play an even more important part in operating than they do in timber cruising with the result that these operations can be carried on much more economically by their application. Some companies which have applied aerial photographs to their logging operations realize this value to such an extent that if photographs are not available, they do not hesitate to obtain them before they start operations in a new locality. 